Revista Iberoamericana, Vol. LXIX, Núm. 204, Julio-Septiembre 2003, 545-553

\title{
EXILIO Y FRONTERA: HACIA UNA POÉTICA DE LA DIÁSPORA EN PABLO ANTONIO CUADRA
}

POR

\author{
NicAsio URBina \\ Tulane University
}

Todo pueblo tiene su historia de migraciones y diásporas, y todo poeta mayor desarrolla una poética, implícita o explícita, que marca de alguna manera toda, o casi toda su obra. En el caso de Pablo Antonio Cuadra (Nicaragua 1912-2002) su poética y su concepto de migración y desplazamiento están íntimamente ligados. La suya es una obra de reflexión a través de la poesía y de poesía que reflexiona, donde el ser nicaragüense ha sido el epicentro de una labor de muchos años. ${ }^{1}$ Me interesa privilegiar en estas páginas dos temas: las últimas investigaciones y teorías sobre la frontera, como espacio de pensamiento del ser y sobre el ser humano; y unas cuantas reflexiones sobre la obra de Cuadra a la luz de este concepto de Frontera, tan importante a lo largo de la historia de la humanidad. En "Introducción a la tierra prometida" el ensayo preliminar de Aventura literaria del mestizaje Cuadra nos recuerda la migración constante de pueblos indígenas en busca de paz o de mejores tierras. ${ }^{2}$ Entonces no existían fronteras ni líneas divisorias, pero muy temprano en la historia de nuestra evolución empezamos a establecerlas. Los pueblos indígenas de todo el mundo han vivido una secuencia de luchas por el dominio de los territorios, lucha que continúa hoy en muchas partes del planeta. Todas las formas de vida son de alguna manera territoriales. Los animales marcan su territorio con el olor de la orina y de las glándulas, los seres humanos establecemos mojones, demarcamos territorios, deslindamos, y cuando la situación llega a ser desesperante, erigimos alambradas y murallas. La necesidad de proteger nuestro territorio es imperante y fatal. Creemos salvaguardar nuestra seguridad, nuestro bienestar, nuestra tranquilidad; pero al mismo tiempo, nos encerramos en nuestra paranoia, nos atemorizamos ante el "otro" que está afuera y debe quedarse afuera. La seguridad que ganamos la perdemos en apertura. La historia ha demostrado que ni fronteras, ni murallas, ni el mar embravecido pueden detener

\footnotetext{
${ }^{1}$ La obra de Pablo Antonio Cuadra consta de los siguientes libros fundamentales: Poemas nicaragüenses (1934), Hacia la Cruz del Sur (1936), Breviario Imperial (1940), Canto temporal (1943), Poemas con un crepúsculo a cuestas (1952), La tierra prometida (1952), El jaguar y la luna (1959), Zoo (1962), El nicaragüense (1967), Cantos de Cifar (1971), Por los caminos van los campesinos (1972), Esos rostros que asoman en la multitud (1976), Siete árboles contra el atardecer (1980), Torres de Dios (1986) Aventura literaria del mestizaje y otros ensayos (1988), El hombre, Dios nacido en exilio (1991), Exilios (1999), y Nicán Náuat (2000).

${ }^{2}$ Volumen 11 de las Obras en Prosa. San José: Libro Libre, 1988. pp. 13-33.
} 
al emigrante. Recuerden aquella bella parábola de Borges “La muralla y los libros” donde afirma "la muralla en el espacio y el incendio en el tiempo, fueron barreras mágicas destinada a detener la muerte” (Tomo II, 11-3). Ni la muerte ni la migración se pueden detener. Somos un universo en diáspora. Si algo nos está demostrando esta posmodernidad globalizada es que todo es flotante: ¿Dónde radica ahora la cultura? ¿Dónde afianzar las identidades? ¿Dónde y cómo ser nicaragüense o costarricense? Los EE.UU. tienen 3000 $\mathrm{Km}$. de frontera con México, $3000 \mathrm{Km}$. de constante movimiento, de ir y venir de gente y de carga, documentados e indocumentados, importaciones y exportaciones legales e ilegales. Más de cuatro millones de personas consideran que su patria es el "bordo", así en Spanglish, “bordo” ese espacio de tierra indefinido, cortado a veces por un río a veces por un muro, a veces por un desierto insondable. Ahí viven más de cuatro millones de personas que piensan que los gobiernos en ambos lado de la frontera son aparatos represivos y antagónicos, que en ningún momento están interesados en los problemas y las vicisitudes de la gente del "bordo”, y por lo tanto no tienen ningún interés en resolver sus problemas. La frontera entre Nicaragua y Costa Rica, o entre Nicaragua y Honduras, son territorios abandonados por sus gobiernos, carentes de servicios sociales, abandonados a la fluidez constante de la frontera. La función de los gobiernos es mantener un sistema de controles y de leyes que, de alguna forma, satisfaga las necesidades nacionalistas de sus votantes. Los ciudadanos necesitamos saber que hay instrumentos de control que están obligando a los mexicanos o a los nicaragüenses a quedarse en su territorio. Queremos y exigimos que nuestro gobierno nos proteja, y proteja las condiciones de vida que imperan en nuestro país. Exigimos que nuestro gobierno nos ampare de la invasión masiva con que el país, al sur o al norte, al este o al oeste, nos amenaza a cada paso. Ahora bien, para los que viven en ese espacio fronterizo, para los niños que viven en Reynosa pero van a la escuela en McCallen, la dinámica de inclusiones y exclusiones es totalmente diferente. Para ese niño no hay una afuera y un adentro, México es donde está el hogar, donde se va a dormir y a jugar con los amigos del barrio, y los EE.UU. es la escuela, es el lugar donde mami y papi trabajan, es el lugar donde voy al doctor o donde me compran algún juguete o ropa. Los espacios y la redistribución de los espacios en la mentalidad fronteriza son muy diferentes, y también los son las alianzas, los pactos, los compromisos, el patriotismo y la nacionalidad. Esto es muy importante. Pocos factores son tan determinantes en nuestro tiempo como este concepto de frontera. En nuestro siglo xxi estamos viviendo una serie de procesos de redefinición sumamente importantes. Por un lado se conforman grandes grupos económicos, se firman tratados de libre comercio, se da por tierra con las fronteras y los puestos de control, haciéndonos pensar que todos somos ciudadanos del mundo. Por otro lado, nuestro querido siglo xxi está demostrando que los odios étnicos son más profundos que lo que creíamos, que es muy fácil odiar a nuestro hermano, y que cientos de años de historia pueden surgir intempestivamente a la menor provocación, causando guerra y derramamiento de sangre. Los encuentros y los pactos entre países deben ir marcados por la verdadera comprensión entre los pueblos.

¿Qué es la Patria? cabe preguntarse en este siglo xxI. Una respuesta posible la encontramos en “Riverside”, uno de los poemas más hermosos que Pablo Antonio Cuadra le dedicara a la poética del exilio y la frontera. La patria ahí se define como el lugar pensado por los que nos precedieron, pero es también “el polvo de ese bus lleno de nicaragüenses 
que cruzaron el río” (Exilios, 28). La patria en el siglo xxi ya no podemos situarla en virtud de un perímetro geográfico, este es el siglo de los desplazamientos, de la Internet y de la nacionalidad virtual. ${ }^{3}$ ¿A quién le importa ya la localidad cuando es tan fácil irse y regresar? Cada día estoy más convencido que el nacionalismo es el discurso del tirano que quiere entronarse en el poder, que quiere utilizar la amenaza del otro, para esconder su propia dominación hegemónica. Los conflictos fronterizos que tiene actualmente Nicaragua con Costa Rica y Honduras son el gran parte fruto de gobiernos autoritarios, miopes e ilusos, que como Shih Huan Ti en el texto borgiano, pretenden instaurarse como el principio y el fin.

El exilio político es una consecuencia de esta paranoia nacionalista. Cerrar las fronteras, apresar a los adversarios o exiliarlos, pero de cualquier manera silenciarlos. Expulsar a los moros y a los judíos en la España del siglo xv, exterminar a los indígenas americanos o esclavizar a los africanos, matar argelinos independentistas, llenar los campos de concentración, perseguir a los japoneses durante la Segunda Guerra Mundial o sospechar de cualquier árabe en un aeropuerto, son todas formas inanes de defender la Patria, la nacionalidad, la identidad.

Toda literatura de una forma u otra contribuye a la formación de una "comunidad imaginada”, en el sentido que le da Benedict Anderson en Imagined Communities. Ciertos escritores influyen más que otros en la formación de ese imaginario, ya que sus mitos y sus metáforas traducen certeramente el sentir de un pueblo. En el caso de Nicaragua, creo que es en Pablo Antonio Cuadra donde el mito de la nicaraguanidad aparece con toda su fuerza, dando forma y aliento a una de las obras poéticas más importantes de América Latina. La obra de Cuadra es una obra fundacional de la nacionalidad nicaragüense, de las raíces de ese imaginario cultural, de la esencia qué ha pasado a representar lo nicaragüense. Claro está que estos elementos no tienen por qué ser los privilegiados en una escala de valores. Podríamos y deberíamos mirar a todos los subgrupos nacionales, ya que cada uno contribuye de forma inaplazable al mosaico nacional. Es un hecho, sin embargo, que la historia del siglo xx ha estado marcada por la dominación hegemónica de una clase criolla, patriarcal, conservadora, de la que Cuadra es uno de los principales intelectuales. Entre los mitos que trabaja la obra del poeta, me interesa la búsqueda de la tierra prometida como búsqueda de la identidad nacional, como búsqueda de las raíces en la cultura popular y la tradición. Este es uno de los principales motivos de toda la obra de Pablo Antonio Cuadra.

En mi estudio de "Poemas nicaragüenses", publicado por Jorge Eduardo Arellano en Pablo Antonio Cuadra. Valoración múltiple (182-92) señalaba yo una relación importante entre el canto y el desplazamiento, en un argumento que se resume más o menos así: En Poemas nicaragüenses Cuadra desarrolla una visión mítica de la poesía y el canto, propone una poética basada en la reconstrucción de un pasado idílico, en la preservación de las palabras mágicas, de la evocación de una historia y un espacio físico que se realizan en el espacio del discurso poético, en una representación de la historia. Así, se establece

\footnotetext{
${ }^{3}$ Dos textos fundamentales de principios de los noventa que inciden sobre este tema es la colección de ensayos Nation and Narration de Homi Bhabha. New York: Routledge, 1990; y el libro de Benedict Anderson, Imagined Communities. Reflection on the Origin and Spread of Nationalism. London: Verso, 1991.
} 
una relación entre “canto” y “peregrinación”, “poema” y “migración” que es fundamental para entender la poética de Cuadra y la red de relaciones discursivas que se establecen en su obra. El canto es la figura que alberga los desplazamientos, los cambios que se han operado a lo largo de la historia, y la función del cantor es recordar esos desplazamientos, dar testimonio de esa búsqueda y establecer su significación. De esta forma, existe una relación semiótica directa entre la migración ancestral ocurrida en los albores de la historia y la función del canto. El momento de la migración contiene en sí el proceso de búsqueda, la activación de una certeza, de una intuición previa, sobre la existencia del objeto buscado. El discurso poético es así una “promesa”, registra la existencia de un espacio de promisión hacia el cual se ha de caminar, hacia el que se dirigen las huellas del andar y las del poema, las marcas de la enunciación, los signos. Alimento y libertad es el contenido de esa promesa, representámenes de la Tierra Prometida y de la significación del andar. Tanto en su sentido literal como en su sentido mitopoético, alimento y libertad guían la búsqueda del sujeto, son el contenido de la promesa. El valle fértil, pródigo en alimentos y libre de opresión y dominio, se refiere tanto al contenido de un discurso histórico como al contenido de un discurso poético. Literalmente el poema evoca la migración náhuatl provocada por las invasiones aztecas en el siglo Ix, memorial inolvidable de un pasado azaroso, y la búsqueda de la tierra de promisión; pero también se desdobla su significación apuntando a la creación poética, al espíritu del canto, a la riqueza semántica del discurso y su realización como ejercicio de la libertad. De esta forma se ve claramente la red de significaciones que se establece entre el canto como registro y lugar de la significación, y la historia como registro y lugar de los desplazamientos históricos, inscritos a su vez en un discurso que es la historia. El discurso poético es el lugar de convergencia de ambos, contiene y a la vez realiza la promesa, transmite los signos de promisión y al mismo tiempo ofrece el espacio para la realización de esa promesa.

Ahora bien, en su penúltimo libro publicado bajo el título Exilios (1999), encontramos una colección de 14 poemas escritos en la década del ochenta, donde Pablo Antonio Cuadra nos brinda una visión poética y humana del exilio en sus diversas manifestaciones, y corrobora esa conceptualización del poema y la migración, que veo yo desde la época de Poemas nicaragüenses (1934). El poema final de esta colección, titulado "Exilios" contiene el grave dilema del emigrante, el impulso de partir y la voluntad de quedarse. Este dilema es seminal para toda la psicología del exilio, nadie que haya algún día emigrado, podrá sustraerse a ese desgarramiento: desgarramiento de partir y desgarramiento de quedarse. La represiva realidad nos impele a partir, a buscar la vida en otro lado; el amor a la tierra nos compele a quedarnos, a morir en nuestro suelo materno. Así se destroza la unidad del individuo. Pocos versos resumen mejor la contradicción del exilio que el siguiente silogismo: "Entonces quisiera ser extranjero/para regresarme a mi patria” (36). Bello dístico que encierra el deseo y la realidad, el ansia de paz y la urgencia de identidad. Aquí el /gallo/, a diferencia de dos poemas que glosaré a continuación, no importa significados bélicos, son simplemente la marca matutina, el canto que inicia el día en el que nos damos cuenta otra vez que el dolor es permanente, que la tragedia se repite, y que una vez más estamos asediados por la urgencia de partir. Hermosísimo poema que reivindica la más fiera libertad y la más ardua entereza. Esta disyuntiva es la idea central en otro poema de la colección titulado "Una o dos cartas”, aunque ahora la perspectiva es 
desde el exilio, desde la otredad de una tierra extranjera y desconocida, desde donde deberemos volver a la tierra querida.

"Bebedor de tinieblas" es un llamado a salir del exilio interior, a abrirse al mundo, al misterio y a la realidad. En este poema se combina el uso del signo /bebedor/ tomando en consideración primordialmente su contexto alcohólico, con su sentido de inconciencia y embotamiento. El bebedor de tinieblas se embriaga con la tristeza del exilio y la soledad, se refugia en sus tinieblas negándose a volver al mundo de donde ha sido arrojado. Este lindo y breve poema es una invitación a enfrentar lo nuevo y lo misterioso, una exhortación a no refugiarse en pasados remotos y solitarios, a no encerrarse en la oscuridad del nacionalismo, de la droga, del orgullo o el alcohol. "El misterio es real” dice el poeta, hay que abrirse al misterio, “Alúmbrate”, metáfora rica y vigorosa. En un tiempo de poesía sin metáfora, Cuadra nos hace un llamado a la imaginación metafórica, a la apertura, a la realidad que es también y fundamentalmente metafórica.

En “Palo de limón” y “Un redoble de tambor para el viejo Roque”, el signo central es el /gallo/, con su carga bélica, su belleza y su masculinidad, su simbolismo atávico y su historial. El viejo gallo Roque que con su espuela y su pico hace la guerra, incita a la violencia, mata, pasa a representar una dimensión del ser nicaragüense, esa dimensión oscura y altanera de su imaginario social, la necesidad de luchar e imponernos, de vencer. Si el/gallo/representa el espíritu bélico, el/limón/ es la sangre agria y amarga que alimenta la guerra, es la sangre de la espada, la dorada inquietud de la revancha. Estos dos poemas son importantísimos para la formulación de una cartografía nacional, porque definen, en forma poética, y a través de dos metáforas hermosísimas, la intensa relación de los nicaragüenses con la guerra. Lucha constante por reafirmar su masculinidad, por marcar su territorio, por defender su identidad, tanto el gallo como el nicaragüense se ven impelidos a descender del árbol y caminar hacia la muerte. De ahí la doble metáfora del limonero que crece en el patio y el limonero que crece en el sueño.

"El hijo pródigo" es la re-escritura de la famosa parábola bíblica pero desde el punto de vista del héroe, no del padre; y el regreso no es a la riqueza y la comodidad, sino a la belleza. Este poema juega magistralmente con la imaginación y la realidad, y establece una dicotomía entre la memoria y la mirada. Cada recuerdo encuentra su contrapartida en una realidad deslustrada y empequeñecida, reducida por el tiempo y el desgaste. Sólo la belleza intelectual se conserva viva en el misterio rotundo de un beso, capaz de revivir después de muchos años de ausencia, capaz de ser en cualquier momento, de nuevo y una vez más, con toda su intensidad, aunque nosotros ya no seamos más que cenizas de recuerdo. Lindo poema, lleno de misterio y de dolor, que remite a la críptica relación entre el recuerdo y la mirada, el insondable encuentro del retorno y la especial esencia de la belleza.

El poema titulado "E.T." inmediatamente nos remite a la modernidad cinemática de Spielberg aunque siempre nos asalte la duda que tras las crípticas iniciales se encierre otra cifra. Breve poema, escrito en Texas, en 1986, donde el exilio que se canta en el poema es el exilio del hombre frente a la mujer, esa imposibilidad de ser, de penetrar, de entender la esencia femenina, la humedad y la fragancia. Hombre y mujer como elementos separados, hecho a una misma imagen con materiales disímiles, a veces incompatibles. En este poema el sujeto se separa de la mujer que ama en virtud de una diferencia siempre inalcanzable. Como la diferencia derrideana del lenguaje, hombre y mujer luchan por encontrarse, por compenetrarse, pero, inevitablemente, siguen siendo extranjeros. 
“La isla de los Centauros”, el poema más extenso de la colección, es una reflexión sutil e inteligente sobre la violencia y la guerra. La fuerza ha derrotado a la inteligencia, la belleza ha sucumbido bajo el casco de la herida. Rubén es la figura que se percata del horror y trata de salvar la dignidad de los hombres. Poema dialógico, conversacional, que retoma la estructura del famoso "Coloquio de los Centauros” de Darío para presentarnos el estado de la patria en la década del ochenta. Los preclaros y honrados centauros que un día defendieron la libertad y la justicia, se han convertido ahora en asesinos, han dilapidado los bienes, han manchado con sangre inocente sus cascos y han arrojado saetas a los niños. Ahora sólo reina la violencia y la venganza, la violación y la muerte. Los jóvenes han sido enviados a la guerra y toda la nación se ha cubierto de luto. Sólo la hembra dice la verdad, sólo la madre es capaz de levantar su voz por encima del dolor y denunciar a los raptores. Poema de graves sonidos y oscuros colores, "La isla de los Centauros" cuestiona a través de Darío la historia y la vida.

Pocos poemas tan bellos como "Canto al atardecer de una revolución” donde la historia de América se resume en función de sus revoluciones, de sus cruentas batallas, de sus traiciones. Desde Junín hasta nuestros días, la imagen de América es forjada por una revolución que embiste contra otra revolución, y así, entre guerra y guerra, se forja la estirpe del continente. En ciclos infinitos y en silencios de muerte, en dualidades que no conocen término, en dominios de dominios de dominios. Pero la gran sabiduría del poema no radica en la Historia, radica en el corazón. Sólo con ese corazón revolucionario, dispuesto siempre a cambiar, a revaluar, a perdonar, se podrá superar esta secuencia de atardeceres que caen sobre cada revolución. "Diariamente brilla en tu mente una revolución / que debe ser superada en tu corazón por otra revolución” (27).

La tragedia del éxodo se reconstruye poéticamente en "Riverside", ese poema magistral donde el /río/ y el /polvo/ funcionan como signos de la peregrinación, de la continuidad y del obstáculo. Pablo Antonio Cuadra maneja en este poema las dos figuras fundacionales de la Patria: Rubén Darío y Augusto César Sandino, ambos en un camino, en un desplazamiento que los ha de llevar a la vida y a la muerte. Imágenes certeras y bellísimas de una fundación nacional, que luego habrán de prolongarse en la lucha de los nicaragüenses por subsistir dentro y fuera de la Patria. Escrito en Texas, en 1988, este poema se preocupa por el problema de la migración a los Estados Unidos donde el río es la marca fronteriza de la separación. Poema de hondos y profundos sentimientos, donde el recuerdo del rostro de la madre es la imagen de la Patria, y el llanto es la poesía del dolor. "Riverside" es un gran poema, composición antológica que quedará como testimonio imperecedero de esa década en la historia de Nicaragua, marcada por la esperanza y la decepción.

"Una joven madre llora en la puerta de mi Patria” es el poema que establece el locus del canto. Esos ojos campesinos de madre tierna son el lugar que el poeta privilegia para su entonación. Nada se compara con esos ojos y ese llanto. Los ojos, que miran la tierra que ya no podrá tocar son el espacio ideal para que el lenguaje, que no podemos tocar, enuncie la tierra ausente. En esa dicotomía de ausencia-presencia se cifra el misterio de la poesía y se compone la tragedia del exilio. La enunciación del canto se instala en la mirada que llora y anhela, y de esa forma, dos acciones intangibles, reflejan la tragedia del destierro. 
Este poemario está dominado por el tono grave y premonitorio, con la excepción de "El nuevo tiempo", donde lo que domina es la ironía y la tristeza. El verdugo que se erige en juez y en profeta, el gobernante que con la espada pretende construir al hombre nuevo, el padre que castiga en nombre del amor. "El nuevo tiempo" encierra en sus ocho versos una apología del error y la falibilidad. Sólo los que nos equivocamos somos capaces de acertar, porque los que se creen incólumes sólo podrán construir infiernos, paraísos inhabitables. Esta idea se presenta más abiertamente en “1984”, poema más expositivo que lírico, escrito con la indignación de la injusticia.

El gran problema del análisis generacional de la literatura es que no logra explicar la amplia envergadura que la obra de un poeta puede abarcar. Decir que Pablo Antonio Cuadra es un poeta de Vanguardia es limitarlo a una etapa, importante pero parcial de su obra. Exilios nos vienen a mostrar que Cuadra es un poeta finisecular y posmoderno, ya que en las postrimerías del siglo xx en que fue escrito, el problema de identidad y de la migración, del desarraigo y el nacionalismo, de las fronteras que unen y separan, establecen los vértices centrales de la polémica. En estos poemas nos demuestra que los signos del canto y el poema son el espacio del origen, en ellos se encierra el conocimiento del principio, de la migración y el desplazamiento, de una Tierra de Promisión o un Paraíso Perdido, de un lugar en que habrán de realizarse los sueños, las promesas del canto, los signos del poema, y una tierra de la que hay que partir para huir del horror. Ante tanto movimiento, tanto azar y tanta migración, se erige enhiesta la casa junto al lago, espacio estable y firme, centro matriz de una tradición y una genealogía, albergue hospitalario ante la represión y la muerte, dadivoso hospicio ante la pobreza. Y desde ahí la voz del poeta va recogiendo los gemidos de su tribu a lo largo de la historia, y la poesía de Cuadra, como lo demuestran su sólida y extensa obra, alberga los gemidos de todo un siglo.

Los últimos veinte años nos han dejado un vasto corpus textual de "teorizaciones" sobre la frontera. No voy a repasar aquí este vasto territorio trazado por filósofos y críticos. Quisiera solamente referirme al libro de Walter Mignolo Local Histories/Global Design. Mignolo introduce en este libro el concepto de "border gnosis" que podemos traducir como "gnoseología de la frontera”, y que viene a ser "la razón del subalterno luchando por poner en el centro del debate los conocimientos "subalternizados” por los procesos de colonización del planeta, que coincide con la consolidación de la razón moderna”(13, traducción mía). Desde esa tierra de nadie que es la frontera, el campesino nicaragüense, que cruza al otro lado para comprar fósforos, aceite y aspirinas, pone en jaque todo el aparato represivo fronterizo, demostrando que las líneas que dividen el afuera y el adentro son ilusorias, fanáticas e inservibles. Si en lugar de erigir murallas y puestos fronterizos, erigimos escuelas y hospitales, creamos fuentes de trabajo y les damos tierra y financiamiento para trabajar, el habitante de la frontera crece y progresa, hace su patria en la frontera, ese espacio se convierte en un "locus agradable” como decía Berceo, se da un gran paso en la resolución del conflicto. Nuestro tiempo se caracteriza por la gran movilidad de las poblaciones. Recientemente, en un número del PMLA ${ }^{4}$ dedicado a las poblaciones flotantes del planeta, Ian Chambers habla del dilema de la posmodernidad con relación a la ciudadanía, la lengua y la modernidad. D. N. Rodowick presenta el dilema brillantemente

\footnotetext{
${ }^{4}$ Publication of the Modern Language Association of America.
} 
cuando habla de “ciudadanos móviles en una era de estados mediatizados”. Movilidad es la palabra clave en este tema de la Frontera. Como los teléfonos móviles, nuestra situación es cada día más volátil, más flotante, nos desplazamos con gran agilidad. En la frontera esa movilidad es todavía más significativa por el juego constante de las naciones y su relación con los territorios ocupados, y por el continuo entrar y salir de un territorio y otro. Siguiendo a Rodowick podemos decir que “La Globalización está produciendo el flujo de mercancías y capitales por todos lados, los conglomerados de redes informativas son controlados por un grupito de corporaciones multinacionales, y al mismo tiempo se están produciendo comunidades internacionales desterritorializadas, donde las identidades culturales son casa vez más fluidas y multidimensionales, las culturas y las etnias se están mezclando localmente y se redefinen a través del consumo de culturas transmitidas por las redes globales” (16, traducción mía). La ciudadanía es una construcción cultural que también está cambiando en este siglo xxı. Gerard Delanty también ha hecho importantes contribuciones a este tema en su libro Citizenship in a Global Age, y Guillermo Gómez Peña ha definido la frontera no como un marco o un territorio más o menos estable, sino como un segmento móvil, en continuo desplazamiento. Nuestros pobladores de las regiones fronterizas viven en ese paradigma, se mueven libremente de un territorio al otro, eludiendo fácilmente los controles estatales, yendo y viniendo según una serie de necesidades laborales y de sobrevivencia. ¿Cómo puede definirse en tanto que nicaragüense o costarricense, hondureño o salvadoreño, un sujeto que constantemente está en la franja, cambiando de un lado a otro, estudiando en un lado, viviendo en otro, comprando en otro?

Pablo Antonio Cuadra, hacia el final del siglo y casi al final de su vida, escribió poemas que marcan y resumen la dialéctica de nuestra posmodernidad. El epílogo de Exilios es una muestra de la ponderable reflexión de un nicaragüense, que desde la diáspora piensa su tierra y su gente. Pocos escritores han dejado una herencia tan hermosa a su pueblo como la veintena de títulos que nos heredó Cuadra. La poética del canto y la poética del desplazamiento, de la migración, de la huida, de la diáspora, y ante el desastre de los gobiernos, ante el saqueo indiscriminado, ante la violencia de la pobreza y la corrupción de las instituciones, repetimos: "Entonces quisiera ser extranjero / para regresarme a mi patria”.

\section{BibliografíA}

Anderson, Benedict. Imagined Communities. Reflection on the origin and Spread of Nationalism. London: Verso, 1991.

Arellano, Jorge Eduardo. Pablo Antonio Cuadra. Valoración múltiple. Managua: Troqueles, 1994.

Borges, Jorge Luis. Obras completas. 3 Vols. Buenos Aires: Emecé, 1989.

Chambers, Iain. “Citizenship, Language, Modernity”. PMLA 17/1 (January 2002): 24-31. Cuadra, Pablo Antonio. Aventura literaria del mestizaje. San José: Libro libre, 1988. Exilios. Managua: Academia Nicaragüense de la Lengua, 1999.

Gómez Peña, Guillermo. Dangerous Border Crossers: The Artist Talks Back. New York: Routledge, 2000. 
Mignolo, Walter. Local Histories/Global Design. New Haven: Princeton University Press, 2000.

Rodowick, D.N. “Introduction: Mobile Citizens, Media States”. PMLA 17/1 (January 2002): 13-23. 